\title{
Politik Wacana pada Berita Pilpres 2019 di Media Daring Vivanews.com
}

\author{
Farida Yufarlina Rosita* \\ Tadris Bahasa Indonesia, IAIN Surakarta, Surakarta, Indonesia \\ Email:fyrosita@gmail.com \\ Marfu'ah Nur Jannah \\ Tadris Bahasa Indonesia, IAIN Surakarta, Surakarta, Indonesia \\ Email:18jannh@gmail.com
}

\begin{abstract}
This study is intended to identify forms of the 2019 colloquial language expressions in vivanews.com's online media, which focuses on word selections, includes:(a) value-experimentation, (b) relational value and (c) expressive value. The method used is a critical wacana analysis. Research indicates an optional word on the experimental value of the experimental value found in the 2019 online media vivanews.com, where dramatic, powerful, persuasive, and communicative words are used. The wording of a relational value, that is, use of suggestion, a formal word consisting of a foreign vocabulary, and an informal word as a mixture of local languages. And an expressive value choice is more expressing a negative evaluation word. This study also asserted that the use of language is not neutral, but it has hidden interests. By word choice and news content presented, vivanews seemed to expand political support on certain candidates by presenting poorly the opposing candidates. Therefore, research suggests the importance of critical awareness to the reader.
\end{abstract}

Keywords: online media, election, discourse, language use, politics.

\begin{abstract}
Abstrak. Penelitian ini bertujuan untuk mengetahui bentuk ekspresi bahasa berita Pilpres 2019 dalam media daring vivanews.com yang terfokus pada pilihan kata meliputi: (a) nilai eksperiensial, (b) nilai relasional serta (c) nilai ekspresif. Metode yang digunakan adalah aanalisis wacana kritis. Hasil penelitian menunjukan pilihan kata pada nilai eksperiensial yang terdapat dalam berita Pilpres 2019 di media daring vivanews.com, yaitu menggunakan kata-kata dramatis, tegas, meyakinkan dan komunikatif; pilihan kata pada nilai relasional, yaitu menggunakan kata saran, kata formal berupa kosakata asing, dan kata informal berupa campuran bahasa daerah; dan pilihan kata nilai ekspresif lebih mengekspresikan kata evaluasi yang bersifat negatif. Penelitian ini juga menegaskan bahwa penggunaan bahasa tidaklah netral, tapi mengandung kepentingan tersembunyi. Melalui pilihan kata dan sumber berita yang ditampilkan, vivanews.com tampak memperluas dukungan politik pada kandidat tertentu dengan menampilkan secara buruk kandidat lawan. Oleh karena itu, penelitian menyarankan pentingnya kesadaran kritis bagi pembaca.
\end{abstract}

Kata Kunci: Media daring, Pilpres 2019, wacana, penggunaan bahasa, politi

*Penulis Korespondensi 


\section{PENDAHULUAN}

Bahasa adalah sistem lambang bunyi arbitrer yang digunakan manusia untuk berhubungan satu dengan yang lain, untuk berinteraksi, dan menyampaikan informasi. Dalam hal ini, Achsani, (2019) menegaskan bahwa bahasa digunakan manusia untuk mempermudah kegiatan berkomunikasi serta mengutarakan gagasan, pendapat, dan perasaan. Halliday (1975) menyebutkan bahwa bahasa memiliki 7 (tujuh) fungsi komunikasi, yakni fungsi personal, regulator, interaksional, informatif, imajinatif, heuristik, dan instrumental. Namun demikian, fungsi utama dari sebuah bahasa adalah untuk fungsi komunikasi.

Salah satu bentuk komunikasi tulis adalah teks atau wacana. Wacana merupakan unsur pembentuk bahasa tertinggi setelah fonem, morfem, kata, frasa, klausa, kalimat, dan paragraf. Ini sejalan dengan pendapat Kridalaksana, (2008) yang menyatakan bahwa wacana merupakan satuan terlengkap dalam hierarki gramatikal tertinggi. Dalam wacana, terdapat nilai, kategori, dan sudut pandang. Sudut pandang tersebut berkaitan dengan kepercayaan atau pandangan dunia yang merupakan representasi dari sebuah pengalaman. Produksi sebuah wacana berkaitan erat dengan latar belakang dan konstruksi yang dibentuk oleh penulis (Fitriana Riri Amanda, 2019).

Berita adalah laporan tercepat berkaitan dengan fakta atau opini yang mengandung hal penting dan yang menarik minat bagi sejumlah besar penduduk (Maiyulinda, 2018). Berita adalah informasi baru atau informasi mengenai sesuatu yang sedang terjadi. Berkaitan dengan dunia tanpa kertas (paperless world), berita atau informasi tentu dapat disebarluaskan dengan menggunakan media elektronik. Bahkan, dengan media elektronik, informasi tidak hanya dapat dikonsumsi dengan cara membaca teks, tetapi juga dapat dengan cara mendengar, menonton, bahkan melakukan interaksi langsung dengan penulis berita seperti biasa terjadi dalam platform media daring.

Situs-situs berita daring seperti www.detik.com, www.kompas.com, www.merdeka.com, www.vivanews.com, dan dll. memberikan berita atau informasi seputar politik, bisnis, hukum, pemerintahan sampai berita-berita yang berhubungan dengan hiburan dengan cara penyajian dan penyampaian yang berbedabeda. Perbedaan tersebut disebabkan oleh perbedaan sudut pandang, perbedaan kepentingan, dan perbedaan gaya penyampaian. Menurut Ary Hunanda Kuswandari, (2017), berita daring memiliki peran yang kuat dalam membentuk pola pikir masyarakat mengenai realitas. Melalui gaya penceritaan sebuah berita, seseorang mendapatkan informasi sesuai dengan yang diinginkan.

Salah satu situs berita daring yang memiliki kriteria tertentu adalah vivanews.com. Vivanews.com merupakan media daring yang bernaung di bawah PT Viva Media Baru anak perusahaan dari PT Visi Media Asia Tbk milik Bakrie Group. Vivanews.com masuk ke dalam situs berita daring andalan mengingat PT Visi Media Asia Tbk adalah perusahaan media konvergensi yang terintegrasi dengan salah satu saluran televisi terdepan di Indonesia, yakni TVOne dan ANTV.

Dalam menyampaikan berita, vivanews.com mengusung tagline terdalam (indepth) dan terpercaya (trusted) yang berarti mengandalkan kedalaman dan keakuratan berita yang disampaikan kepada pembaca. Tidak hanya itu, vivanews.com juga 
mengedepankan pertumbuhan dan perkembangan informasi berita baru dengan cepat sehingga dapat memberikan kontribusi penyaluran informasi terkini kepada masyarakat luas (www.vivanews.com). Vivanews.com juga memiliki fitur U-report pertama di Indonesia, fitur ini memungkinkan pembaca berbagi pendapat mengenai informasi dan isu penting yang telah dibaca kepada pembaca lain.

Informasi yang muncul di masyarakat merupakan hasil dari sebuah konstruksi yang berbeda oleh beberapa media. Ini karena media memiliki ideologi dan kepentingan masing-masing. Akibatnya, seperti dikemukakan (Adhiarso et al., 2017), berita yang disajikan dalam media tidak lagi mencerminkan kebenaran atau fakta sebuah peristiwa karena sudah mengalami proses konstruksi. Oleh sebab itu, untuk memahami sebuah informasi, seseorang dapat melihat referensi yang berbeda sesuai dengan berita yang sudah dikonstruksi oleh setiap media. Ideologi, kepentingan pemilik, dan nilai-nilai yang dipegang jurnalis dan pemilik memegang peran penting dalam kontruksi berita.

Akhir-akhir ini, kekuasaan media massa marak dimanfaatkan untuk kepentingan pribadi (lihat Rianto dkk, 2016). Ini karena media dapat membantu mengontrol dan menyeimbangkan tekanan dari luar sehingga redaktur media akan ikut mendukung penguasa (Efendi, 2014: 1-2), tidak terkecuali media yang berada di bawah perusahaan Aburizal Bakrie. Aburizal Bakrie adalah founder Bakrie Group yang memiliki jabatan sebagai mantan Ketua Umum dan Ketua Dewan Pembina Partai Golkar (Golongan Karya) periode 2016-2019. Ia merupakan tokoh elit politik yang memiliki pengaruh besar terhadap pasangan pilpres Prabowo-Sandi dan Jokowi-Makruf. Pasalnya, pada pilpres 2014, Aburizal mendukung Prabowo, dan kini di pilpres 2019 partai Golkar pindah haluan mendukung Jokowi. Hal tersebut dapat mempengaruhi peyajian pemberitaan pilpres 2019 di media vivanews.com

Pemberitaan akan senantiasa didasarkan pada manajemen keredaksian. Manajemen ini dilakukan untuk menjaga kualitas produk (Fazryansyah et al., 2014). Kualitas produk media massa berkaitan dengan kebutuhan pembaca akan informasi terkini dari surat kabar maupun media. Hal ini nantinya akan berdampak pada rating sebuah media. Oleh karena itu, salah satu yang dapat dilakukan oleh media adalah bagaimana caranya agar pembaca menjadi tertarik dengan setiap bahasa yang dikemas, mengonstruksi pikiran pembaca melalui bahasa-bahasa yang ditulisnya.

Bahasa berita tentu tidak lepas dari konteks. Menurut Sobur, (2009),konteks memasukkan semua situasi dan hal yang berada di luar teks dan mempengaruhi pemakaian bahasa (partisipan dalam bahasa, situasi pemroduksian teks, fungsi yang dimaksud, dan sebagainya). Maka, untuk dapat mengetahui maksud sebuah berita, seseorang dapat melihat ekspresiekspresi bahasa yang digunakan dalam suatu wacana. Ekspresi bahasa tersebut menuntun pembaca untuk dapat mengetahui perspektif atau pandangan media sebagai pembuat berita. Menurut Fairclough, (1995), pilihan kata dalam wacana menandai secara sosial maupun ideologis bidang pengalaman yang berbeda dari penulis berupa nilai-nilai. Nilai tersebut adalah nilai eksperiensial, nilai relasional, dan nilai ekspresif. Nilai ekspriensial terdiri dari pola klasifikasi teks, proses leksikal (generalisasi), proses leksikal (kelebihan leksikal), kata-kata ideologis, relasi makna yang ideologis, dan metafora; nilai rasional terdiri dari ekspresi eufemisme, kata formal, dan kata informal; serta nilai ekspresif sendiri. Hal tersebut menunjukkan bahwa pilihan kata 
tidak sekadar digunakan untuk menggambarkan sebuah berita, tetapi juga merupakan ekspresi atau representasi konsep pembedaan kelas, golongan, ideologi, dan memiliki fungsi kategorisasi.

Penelitian ini mengambil objek wacana berita, khususnya pada bentuk pilihan kata pada pemberitaan pilpres 2019 di media daring Vivanews.com. Beberapa penelitian yang relevan terkait dengan analisis ekspresi berita pernah dilakukan di antaranya oleh Utami, (2019), Mustafa, (2018), dan Prihantoro, (2013). Kajian lainnya fokus pada pidato pejabat kandidat atau presiden seperti dilakukan oleh Persada dan Persada et al., (2018), Sumarti, (2010).

Penelitian ini mirip dengan yang dilakukan oleh Utami, tapi dalam konteks dan instrumen yang berbeda. Analisis difokuskan pada analisis yang bersifat mikro, yakni berita politik selama Pilpres 2019 dengan menggunakan analisis wacana kritis Fairclough. Berita politik sangat penting dalam mempengaruhi preferensi dan gambaran pemilih terkait dengan kandidat. Analisis kritis atas teks berita yang disiarkan vivanews.com ini diharapkan dapat membongkar ketidaknetralan bahasa, sekaligus motifmotif tersembunyi dalam wacana berita. Dengan begitu, penelitian ini diharapkan dapat menyumbangkan bagi upaya membangun kesadaran kritis di antara pembaca terkait dengan berita politik.

\section{METODE}

Penelitian ini adalah penelitian kualitatif yang terfokus pada analisis wacana kritis dalam wacana pemberitaan Pilpres 2019 di media daring vivanews.com. Sumber data primer pada penelitian ini berupa berita wacana Pilpres 2019 di media vivanews.com.

Pengumpulan data dalam penelitian ini menggunakan metode simak dengan teknik baca dan teknik catat. Digunakan metode simak karena memang merupakan penyimakan terhadap wacana. Teknik baca digunakan karena dalam memperoleh data dilakukan kegiatan membaca. Teknik selanjutnya adalah teknik catat, yaitu menjaring data dengan mencatat hasilnya.

Teknik analisis data yang digunakan dalam penelitian ini adalah teknik analisis wacana kritis mengacu pada teori Norman Fairclough. Dalam penerapannya, analisis wacana ini difokuskan pada analisis teks, yang menjadi salah satu dimensi wacana Fairclough untuk melihat hubungan dengan sifat formal teks (Fairclough, 1995). Analisis teks ini dilakukan pada pilihan kata pada sebuah wacana berita untuk melihat tiga hal, yaitu (a) nilai eksperiensial, (b) nilai relasional, dan (c) nilai ekspresif.

\section{HASIL DAN PEMBAHASAN}

Data-data yang diperoleh dan dibahas dalam penelitian ini adalah permasalahan tentang bentuk-bentuk ekspresi bahasa yang muncul dalam wacana pemberitaan Pilpres 2019. Berikut adalah data pemberitaan Pilpres 2019 melalui media daring Vivanews.com dengan lima topik yang berbeda, yaitu (a) Hoaks Ratna Sarumpaet, (b) Debat Capres Keempat Soal TNI, (c) Petugas KPPS, (d) Input Data, dan (e) Setan Gundul. 
Tabel 1. Topik dan Judul Berita

\begin{tabular}{|c|c|}
\hline Topik & Judul \\
\hline $\begin{array}{l}\text { Hoaks Ratna } \\
\text { Sarumpaet }\end{array}$ & $\begin{array}{l}\text { Kena Hoax Ratna Sarumpaet, Prabowo Dinilai Bunuh Diri } \\
\text { Politik }\end{array}$ \\
\hline $\begin{array}{l}\text { Debat Capres } \\
\text { Keempat Soal TNI }\end{array}$ & Kawan di Akmil Sebut Prabowo Tak Paham TNI Era Modern \\
\hline Petugas KPPS & Jumlah Petugas KPPS yang Meninggal Tercatat 440 Orang \\
\hline Input Data & Soal Salah Input, Bawaslu Ingatkan KPU Lebih Hati-hati \\
\hline Setan Gundul & $\begin{array}{l}\text { Lawan Setan Gundul, Fadli Zon: Ada Genderowo di Pihak } \\
\text { Sana }\end{array}$ \\
\hline
\end{tabular}

Pada analisis teks, aspek formal yang diteliti meliputi tiga aspek nilai, yaitu nilai eksperiensial, relasional, dan ekspresif (Indah, 2009) sehingga pilihan kata yang dianalisis dilihat dalam tiga nilai tersebut. Berikut data pilihan kata dalam media Vivanews.com.

Tabel 2. Penggunaan Kata dalam Liputan Pilpres Vivanews.com

\begin{tabular}{|c|c|c|c|c|}
\hline \multirow{2}{*}{$\begin{array}{l}\text { No. } \\
\text { Data }\end{array}$} & \multirow{2}{*}{ Data } & \multicolumn{3}{|c|}{ Nilai } \\
\hline & & Eksperiensial & Relasional & Ekspresif \\
\hline $\mathbf{v} / \mathbf{1}$ & Kena & & $\sqrt{ }$ & \\
\hline $\mathbf{v} / 2$ & Aktivis & $\sqrt{ }$ & & \\
\hline $\mathbf{v} / \mathbf{3}$ & Buntut & $\sqrt{ }$ & & \\
\hline$v / 4$ & $\operatorname{Hoax}$ & & $\sqrt{ }$ & \\
\hline $\mathbf{v} / \mathbf{5}$ & Manuver elite & & $\sqrt{ }$ & \\
\hline $\mathrm{v} / 6$ & Bunuh diri & $\sqrt{ }$ & & \\
\hline $\mathbf{v} / 7$ & Merugikan & & & $\sqrt{ }$ \\
\hline $\mathbf{v} / 8$ & Ngapain & & $\sqrt{ }$ & \\
\hline $\mathbf{v} / 9$ & Postingan & & $\sqrt{ }$ & \\
\hline $\mathbf{v} / \mathbf{1 0}$ & Kayak & & $\sqrt{ }$ & \\
\hline $\mathbf{v} / \mathbf{1 1}$ & Gitu & & $\sqrt{ }$ & \\
\hline $\mathbf{v} / \mathbf{1 2}$ & Enggak & & $\sqrt{ }$ & \\
\hline $\mathbf{v} / \mathbf{1 3}$ & Mantan & $\sqrt{ }$ & & \\
\hline $\mathbf{v} / \mathbf{1 4}$ & Malu & & & $\sqrt{ }$ \\
\hline $\mathbf{v} / \mathbf{1 5}$ & Tidak bagus & & & $\sqrt{ }$ \\
\hline $\mathrm{v} / 16$ & Meragukan & & & $\sqrt{ }$ \\
\hline $\mathbf{v} / \mathbf{1 7}$ & Invasi & $\sqrt{ }$ & & \\
\hline $\mathbf{v} / \mathbf{1 8}$ & Seorang kepala negara & $\sqrt{ }$ & & \\
\hline $\mathbf{v} / 19$ & Doktrin & $\sqrt{ }$ & & \\
\hline $\mathbf{v} / \mathbf{2 o}$ & Akan lebih baik Prabowo belajar & & $\sqrt{ }$ & \\
\hline $\mathbf{v} / \mathbf{2 1}$ & Ketua Umum Partai Gerindra & $\sqrt{ }$ & & \\
\hline
\end{tabular}




\begin{tabular}{|c|c|c|c|c|}
\hline \multirow{2}{*}{$\begin{array}{l}\text { No. } \\
\text { Data }\end{array}$} & \multirow{2}{*}{ Data } & \multicolumn{3}{|c|}{ Nilai } \\
\hline & & Eksperiensial & Relasional & Ekspresif \\
\hline $\mathbf{v} / \mathbf{2 2}$ & Meninggal & $\sqrt{ }$ & & \\
\hline $\mathrm{v} / \mathbf{2 3}$ & Update & & $\sqrt{ }$ & \\
\hline $\mathbf{v} / \mathbf{2 4}$ & Menguras tenaga & $\sqrt{ }$ & & \\
\hline $\mathbf{v} / \mathbf{2 5}$ & Komisioner KPU & $\sqrt{ }$ & & \\
\hline $\mathrm{v} / 26$ & Santunan & $\sqrt{ }$ & & \\
\hline $\mathbf{v} / \mathbf{2 7}$ & Trouble & & $\sqrt{ }$ & \\
\hline $\mathrm{v} / \mathbf{2 8}$ & KPPS & $\sqrt{ }$ & & \\
\hline $\mathbf{v} / \mathbf{2 9}$ & Insya Allah & $\sqrt{ }$ & & \\
\hline $\mathbf{v} / \mathbf{3 o}$ & Ditangkap dan dibawa & $\sqrt{ }$ & & \\
\hline $\mathbf{v} / \mathbf{3 1}$ & Petugas & $\sqrt{ }$ & & \\
\hline $\mathbf{v} / 32$ & Illegal Access & & $\sqrt{ }$ & \\
\hline $\mathbf{v} / \mathbf{3 3}$ & Website & & $\sqrt{ }$ & \\
\hline$v / 34$ & Sim Card & & $\sqrt{ }$ & \\
\hline $\mathbf{v} / 35$ & Ditangkap dan ditahan & $\sqrt{ }$ & & \\
\hline $\mathrm{v} / 36$ & Enggak & & $\sqrt{ }$ & \\
\hline $\mathbf{v} / \mathbf{3 7}$ & Genderuwo & & $\sqrt{ }$ & \\
\hline $\mathrm{v} / 38$ & Masif dan brutal & $\sqrt{ }$ & & \\
\hline v/39 & Pak Prabowo & $\sqrt{ }$ & & \\
\hline $\mathrm{v} / 40$ & Kecurangan & $\sqrt{ }$ & & \\
\hline $\mathbf{v} / 41$ & Politikus & $\sqrt{ }$ & & \\
\hline $\mathrm{v} / 42$ & Setan Gundul & & $\sqrt{ }$ & \\
\hline $\mathrm{v} / 43$ & Menyelamatkan & $\sqrt{ }$ & & \\
\hline & Jumlah & 22 & 17 & 4 \\
\hline
\end{tabular}

Uraian berikut mengelaborasi temuan penggunaan di atas dengan memaparkan secara lebih detil beserta beberapa contoh dalam kutipan berita.

\section{Nilai Eksperiensial}

Analisis atas penggunaan bahasa dengan mendasarkan pada nilai eksperiensial akan dilihat berdasarkan pada ola klasifikasi teks, proses leksikal, kata-kata ideologis, relasi makna ideologis, dan metafora.

\section{Pola Klasifikasi Teks}

Dalam berita Vivanews.com, terdapat pola-pola klasifikasi tertentu yang digunakan untuk menggambarkan realitas tertentu. Berikut pola klasifikasi teks yang tergambar dalam teks berita.

“Apa yang dilakukan Ratna Sarumpaet itu bunuh diri politik. Termasuk Sandiaga Uno dan Amien Rais," ujar Dedi di Bandung, Jawa Barat, Rabu, 3 Oktober 2018. (vivanews.com)

Pada penggalan berita tersebut, penghasil teks mengutip pernyataan Dedi, ketua tim pemenangan dari kubu Joko Widodo-Ma'ruf Amin, yang mengatakan bahwa Ratna Sarumpaet bunuh diri. Bunuh diri merupakan istilah yang digunakan untuk mengklasifikasikan atau menggolongkan kegiatan atau tindakan yang dilakukan secara sengaja untuk menyebabkan kematian diri sendiri. Apa 
yang dipaparkan dalam berita adalah saat Ratna Sarumpaet mengaku bohong dianiaya oleh sekelompok orang yang membuat bagian tubuhnya, khusus di wajahnya menjadi lebam. Penulis, dalam hal ini wartawan vivanews.com, melakukan penegasan dengan mengutip pernyataan Dedi yang menggolongkan Ratna Sarumpaet melakukan kegiatan bunuh diri. Penghasil teks berusaha membangun citra Ratna Sarumpaet melakukan hal yang tidak tepat atau salah.

Pola klasifikasi teks yang lain terdapat dalam kata doktrin dalam kutipan berikut ini.

Saurip menekankan, alih-alih
berkutat kepada doktrin
pertahanan yang tidak
diperbaharui, akan lebih baik
bagi Prabowo untuk mempelajari
konsep pertahanan di era
modern. (Vivanews.com)

Doktrin adalah pendirian satu kelompok ahli ilmu pengetahuan, keagamaan secara bersistem, khususnya dalam penyusunan kebijakan negara. Sementara itu, hal yang disampaikan Vivanews.com mengutip pendapat Saurip tersebut adalah saat Prabowo menjelaskan mengenai doktrin pertahanan yang menurut Saurip kurang tepat. Dalam hal ini, wartawan melakukan menguatan dan penegasan bahwa pengetahuan tentang doktrin atau pendirian segolongan mengenai ilmu pengetahuan yang dimiliki Prabowo akan lebih baik jika diperbaharui.

\section{Proses Leksikal (Generalisasi)}

Generalisasi adalah penyamarataan, bentukan gagasan, ide atau simpulan umum dari suatu hal. Generalisasi yang berlebihan akan menciptakan kesan gaya berpikir yang cenderung kekanakkanakan. Berikut pilihan kata bahasa kekuasaan dalam wujud generalisasi.
"Apa yang disampaikan oleh Pak Prabowo kemarin di depan pers asing juga salah tanggung jawab kita sebagai warga bangsa untuk melawan kecurangan itu. Jadi, di mana-mana kok berbagai bentuk dan modus kecurangan kelihatan. Dari sebelum, saat, dan sesudah pemilu," kata Fadli (Vivanews.com)

Generalisasi dalam kutipan tersebut terdapat pada kata Pak. Penggunaan kata Pak oleh Fadli Zon yang kemudian dikutip oleh Vivanews.com dalam penggalan berita tersebut merupakan generalisasi. Kata Pak semula bermakna orangtua pria yang lazimnya menjadi kepala keluarga dan pencari nafkah. Namun, makna kata Pak tersebut kemudian diperluas sehingga kata Pak pada kutipan tersebut adalah sebutan bagi pria yang dianggap umurnya lebih tua atau dihormati. Kesan yang timbul dalam penggalan berita di atas adalah Fadli Zon menghormati Prabowo.

\section{Proses Leksikal (Kelebihan Leksikal)}

Kelebihan leksikal (overlexicalization) terjadi apabila terdapat penggunaan yang melimpah dari istilah-istilah untuk objek atau konsep tertentu. Berikut wujud kosakata kelebihan leksikal pada teks berita Pilpres 2019 di media sosial.

Ia menambahkan, jika ada perbedaan dan data maka menjadi hal biasa dalam situasi saat ini. Tapi pastinya semua pihak mengakui adanya kecurangan yang masif dan brutal. (Vivanews.com)

Masif memiliki makna kuat, kukuh, padat, di dalamnya tidak berongga. Dalam konteks pemberitaan Pilpres 2019 ini, kata masif diartikan sama seperti kata massive yang berarti besar-besaran (dalam skala kuantitas, tingkat, intensitas, dll), terus- 
menerus tanpa henti. Sementara brutal menunjukkan maksud kejam, kurang ajar, tidak sopan, kasar, dan biadab. Dalam kutipan tersebut, penulis berita dalam hal ini wartawan Vivanews.com mengutip pendapat Fadli Zon, menyampaikan bahwa terdapat kecurangan dalam proses pemilihan presiden 2019 yang dilakukan oleh kubu capres 01 secara kejam dan besar-besaran. Kata masif dan brutal digunakan bersamaan dan disejajarkan untuk menunjukkan sesuatu yang berlebihan.

\section{Kata-kata Ideologis}

Dalam pemberitaan Pilpres 2019 ini, banyak kata-kata ideologis yang digunakan. Kata ideologis berarti kata-kata yang berkenaan dengan ideologi atau pemikiran. Kata-kata ideologis akan sering digunakan dan dimunculkan oleh penghasil teks. Berikut ini adalah salah satu bentuk kutipan yang menunjukkan bahwa penghasil berita menggunakan kata-kata yang berkenaan dengan ideologi.

Jumlah petugas KPPS yang sakit juga bertambah menjadi 4.602 orang, sehingga total petugas yang sakit dan meninggal sebanyak 5.071 orang. Seperti diketahui, peristiwa banyaknya petugas KPPS yang meninggal dan sakit itu menjadi polemik. Badan Pemenangan Nasional (BPN) Prabowo-Sandi pernah mengusulkan agar kuburan petugas KPPS yang meninggal ini dibongkar dan dilakukan autopsi. (Vivanews.com)

Kata KPPS merupakan singkatan dari Kelompok Penyelenggara Pemungutan Suara. Kata KPPS ditulis berulangulang diikuti dengan penjelasan negatif. Kalimat penggalan dalam kutipan tersebut, dituliskan KPPS sakit dan meninggal sebanyak 5.071. Kata-kata yang diulang tersebut menjadi gambaran bahwa penghasil teks menunjukkan ideologinya dengan usaha meyakinkan pembaca bahwa proses pemilihan umum ini banyak memakan korban.

\section{Relasi Makna yang Ideologis}

Relasi makna berhubungan dengan hubungan makna yang digunakan dalam wacana. Dalam pemberitaan Pilpres 2019 ini, ditemukan beberapa relasi makna yang berupa antonim, sinonim, hiponim, dll. Berikut ini wujud pilihan kata yang mengandung relasi makna yang ideologis dalam media Vivanews.com.

Dedi Hendri, ayah kandung MAA, menyebutkan saat ini sudah berada di Jakarta, untuk menemui dan mendampingi langsung putranya selama menjalani pemeriksaan. Meski ditangkap, namun putra Dedi itu tidak ditahan polisi. Bahkan, tadi malam sudah diperbolehkan pulang dari kantor polisi. ( Vivanews.com)

Penggalan berita tersebut menjelaskan bahwa MAA, remaja yang meretas situs KPU ditangkap polisi. Meskipun demikian, MAA tidak ditahan. Kata ditangkap dan ditahan memiliki kemiripan makna. Ditangkap berarti dipegang dengan tangan atau sesuatu, sementara ditahan berarti tidak dibiarkan lepas. Dalam istilah kepolisian, seseorang yang bersalah akan ditangkap terlebih dulu, kemudian ditahan jika bukti-bukti kesalahannya terbukti benar. Dalam penggalan berita tersebut, penghasil teks ingin menjelaskan dan meyakinkan pembaca bahwa meskipun MAA, si pemuda peretas situs KPU ditangkap polisi, ia tidak ditahan dan diperbolehkan pulang. 


\section{Metafora}

Metafora berarti pemakaian kata atau kelompok kata yang memiliki arti tidak sebenarnya. Di dalam pemberitaan Pilpres 2019 ini, banyak terdapat penggunaan metafora yang digunakan sebagai pilihan kata untuk membuat berita makin komunikatif. Penggunaan metafora oleh penghasil teks juga memiliki tujuan untuk mengunggulkan berita yang disampaikannya, meningkatkan efektivitas komunikasi, dan penciptaan makna. Kutipan berita di bawah ini menunjukkan metafora yang dimaksud.

Ketua tim pemenangan

kampanye Joko Widodo-Ma'ruf Amin di Jawa Barat, Dedi Mulyadi, menilai buntut hoax penganiayaan

Ratna ini berdampak buruk bagi Prabowo-Sandiaga Uno. (Vivanews.com)

Dalam penggalan berita tersebut, penghasil teks menggunakan pilihan kata buntut. Buntut, secara harfiah memiliki arti ekor. Akan tetapi, buntut yang digunakan di sini bermakna efek atau akibat yang diterima karena sebab-sebab tertentu. Penghasil teks ingin menunjukkan bahwa kasus kebohongan Ratna Sarumpaet akan berefek atau berdampak buruk bagi pasangan PrabowoSandiaga Uno.

\section{Nilai Relasional}

Nilai relasional dalam penelitian ini akan dilihat dalam menggunakan dua elemen, yakni ekspresi eufemisme dan kata-kata formal dan informal yang menyolok. Uraian berikut akan memaparkan bentuk-bentuk nilai relasional dalam penggunaan bahasa vivanews.com selama pilpres 2019.

\section{Ekspresi Eufemisme}

Salah satu strategi yang digunakan oleh penulis teks untuk menghindari nilai negatif dari pembaca adalah penggunaan eufemisme. Berikut wujud pilihan bahasa dalam bentuk ekspresi eufemisme dalam teks berita Pilpres 2019 di media vivanews.com.

Saurip menekankan, alih-alih berkutat kepada doktrin pertahanan yang tidak diperbaharui, akan lebih baik bagi Prabowo untuk mempelajari konsep pertahanan di era modern. Saurip berpendapat bahwa Jokowi memiliki pengetahuan tentang pertahanan yang lebih mumpuni dibanding Prabowo dalam debat kemarin (Vivanews.com)

Penghasil teks, mengutip pernyataan Saurip, menggunakan eufimisme untuk mengganti nilai rasa dalam percakapan yang kurang sopan menjadi lebih sopan. Dalam penggalan teks berita tersebut, disampaikan bahwa Saurip merasa bahwa Prabowo tidak paham tentang konsep pertahanan NKRI. Pernyataan tersebut diganti Saurip dengan memberikan saran kepada Prabowo untuk belajar kembali konsep pertahanan dengan kalimat “...akan lebih baik bagi Prabowo untuk mempelajari konsep pertahanan di era modern."

\section{Kata-kata 'Formal' dan 'Informal' yang Mencolok}

Kata-kata formal ditunjukkan melalui pilihan kosakata asing dan kosakata ilmiah yang dapat mendatangkan nada formal. Berikut penggalan pemberitaan Pilpres 2019 melalui media Vivanews.com yang menggunakan 
kosakata asing dan kosakata ilmiah untuk menciptakan kesan formal.

Dedi menambahkan, capres Prabowo juga dipastikan mendapat efek domino karena merespons berita hoax tersebut. Seharusnya, sebagai capres, Prabowo bisa lebih bijak dalam bersikap. (vivanews.com)

Pada penggalan berita di atas, terdapat kata hoax yang merupakan wujud kata formal dalam teks. Hoax merupakan kosakata bahasa asing (bahasa Inggris) yang memiliki arti kabar angin, kabar tidak benar, dan sebagainya. Penggalan teks berikut ini juga merupakan penggunaan pilihan kata bahasa Inggris.

Sebelumnya, seorang remaja asal Kota Payakumbuh, Sumatera Barat, berinisial MAA (19 tahun) ditangkap dan dibawa ke Jakarta oleh petugas dari Direktorat Tindak Pidana Kejahatan Siber Bareskrim Polri, dengan sangkaan melakukan percobaan Illegal Acces terhadap website KPU RI. Namun, dia tidak ditahan. (vivanews.com)

Dalam penggalan berita tersebut, terdapat kata illegal acces dan website. Dalam bahasa Indonesia, illegal acces berarti aksi ilegal dan website berarti laman. Berikut ini juga merupakan wujud atau contoh penggunaan bahasa Asing.

"Masalah Situng, sudah kita ingatkan KPU. Situng agak trouble dalam beberapa kali kan, kita sudah kasih surat ke KPU, agar hati-hati, karena ini persoalannya sangat sensitif," kata Komisioner Bawaslu, Rahmat Bagja di Gedung Bawaslu, Jakarta, Rabu 24 April 2019. (vivanews.com)
Dalam penggalan berita di atas, penghasil teks menggunakan kata trouble. Trouble merupakan bahasa Inggris yang berarti masalah. Penggunaan pilihan kata bahasa Inggris oleh penutur atau narasumber di atas bertujuan menciptakan prestige sosial Si Penutur.

Selain kata formal, kata informal
juga digunakan dalam media vivanews.com. Kata-kata ragam informal biasanya menggunakan bahasa yang lebih santai, akrab, adanya campuran dengan bahasa daerah yang lebih dominan dalam komunikasi, dan penggunaan bahasa saat interaksi itu tidak terlalu menuntut kesantunan bahasa yang berlebihan. Hal tersebut dilakukan jika dua orang komunikan berada dalam satu tingkatan yang sama, baik usia, tingkat dalam keluarga, tingkat ekonomi, maupun tingkat jabatan. Selain itu, pelanggaran terhadap kesantunan bahasa yang digunakan bukan berarti pelanggaran terhadap norma sosial yang berlaku. Hal ini lebih dilatarbelakangi oleh tingkat keakraban dalam interaksi yang sedang berlangsung.

"Sekelas Prabowo juga itu sudah melakukan bunuh diri politik. Ngapain juga memperluas postingan kayak gitu, enggak gitu caranya," kata Dedi. (vivanews.com)

Kata ngapain dalam bahasa formal atau ilmiah memiliki arti 'mengapa'. Penghasil berita mengutip kata-kata narasumber tersebut sebagai hasil wawancara. Selain itu, kata kayak gitu juga memiliki padanan dalam bahasa formal atau ilmiah dengan kata 'begitu' atau 'seperti itu'. Kata 'enggak' memiliki padanan dalam bahasa formal dengan 'tidak'. Penggunaan kata-kata ini menunjukkan bahasa lisan yang disampaikan oleh narasumber sebagai bahasa yang mudah dipahami. 


\section{Nilai Ekspresif}

Evaluasi dalam nilai ekspresif terbagi atas dua macam, yaitu evaluasi positif dan negatif. Berikut adalah wujud atau contoh penggalan teks yang mengandung evaluasi negatif yang terdapat pada media vivanews.com.

Aktivis kemanusiaan Ratna
Sarumpaet mengaku bohong
dianiaya yang membuat heboh di
publik. Dinamika peristiwa ini
dinilai bakal merugikan calon
Presiden Prabowo Subianto yang
sebelumnya membela Ratna.
(vivanews.com)

Dalam penggalan teks berita tersebut, disampaikan bahwa pengakuan kebohongan oleh Ratna Sarumpaet yang membuat hoboh publik merugikan calon Presiden Prabowo Subianto. Pilihan kata merugikan dalam penggalan teks tersebut digunakan oleh penghasil teks untuk memberikan evaluasi negatif terhadap Ratna Sarumpaet. Evaluasi negatif yang lain dalam media Vivanews.com juga terdapat dalam penggalan teks berita berikut ini.

\section{Teman seangkatan capres bernomor urut 02 Prabowo Subianto di AKABRI (Nomor Akademi 70), Mayjen TNI (Purn) Saurip Kadi, menegaskan Prabowo telah membuat TNI malu dalam debat keempat Pilpres 2019 Sabtu kemarin, 30 Maret 2019.}

Menurut Saurip yang juga mantan Asisten Teritorial Kepala Staf Angkatan Darat, meski lama bertugas di TNI, pengetahuan Prabowo tentang dunia militer dan pertahanan, ternyata tidak bagus. (vivanews.com)

Penggalan teks berita tersebut dihasilkan oleh penghasil teks dengan mengutip informasi dari narasumber.
Disampaikan oleh penghasil teks bahwa dalam debat keempat Pilpres 2019, Prabowo telah membuat malu TNI karena pengetahuan Prabowo tentang dunia militer ternyata tidak bagus. Tujuan penghasil teks dalam penggalan teks tersebut seolah memojokkan Prabowo Subianto, Capres yang pernah menjadi AKABRI, justru mempermalukan TNI dengan menggunakan pilihan kata telah membuat TNI malu dan tidak bagus yang termasuk evaluasi negatif.

\section{Politik Wacana vivanews.com dalam Pilpres 2019}

Hasil analisis penggunaan bahasa dengan melihatnya dari sisi eksperiensial, nilai relasional serta nilai ekspresif meneguhkan bahwa penggunaan bahasa selalu terkandung di dalamnya kepentingan dan ideologi. Teks, dalam pandangan Fairclough, (2003), adalah hasil suatu proses. Teks adalah produk dari proses produksi teks, dan karenanya tidak berlangsung secara netral. Konteks sosial juga turut mempengaruhi produksi teks, yang dalam penelitian ini adalah pemilu presiden dan wakil presiden. Oleh karena itu, bagaimana vivanews.com menampilkan realitas politik, dan pilihan bahasa yang digunakan tidak terlepas dari pertarungan kepentingan politik yang mendasarinya.

Dalam pertarungan politik itu, secara sadar, bahasa yang digunakan oleh vivanews.com baik secara langsung (melalui pilihan bahasa yang digunakan wartawan untuk menampilkan realitas) ataupun tak langsung (dengan cara meminjam narasumber) meneguhkan posisi politik Vivanews.com. Baik dalam nilai eksperiensial, relasional, maupun ekspresif, terlihat bagaimana secara sadar Vivanews.com menggunakan bahasa untuk menempatkan subjek dalam posisi yang buruk, dalam hal ini Prabowo Subiyanto. 
Kata-kata tidak bagus, bunuh diri politik, memalukan TNI sebagaimana dipaparkan di atas menunjukkan kesimpulan ini. Hasil penelitian ini meneguhkan apa yang dikemukakan Fairclough, (2003), "melalui caranya memposisikan pembacanya, misalnya, diskursus media dapat menerapkan sebuah pengaruh yang kuat dan luas dalam reproduksi sosial karena meluasnya media massa modern..”.

Di sisi lain, perlu juga dipahami bahwa politikus adalah agen konstruksi wacana aktif dalam menggunakan bahasa sebagai instrumen memperjuangkan agenda politik. Studi-studi mengenai hal ini telah banyak dibahas, dan menemukan bagaimana para politikus menggunakan bahasa dalam pidato politiknya untuk tujuan-tujuan persuasif (Rezaei \& Nourali, 2016). Bahasa juga digunakan sebagai bagian dari strategi politik. Studi Sumarti terhadap pidato-pidato Presiden Soesilo Bambang Yudoyono (SBY) menyimpulkan bagaimana SBY menggunakan bahasa sebagai bagian dari strategi politiknya. Hal itu terefleksi dari penggunaan kata, kalimat, dan kiasan. Menurut Sumarti, penggunaan bahasa ini tidak hanya membantu pemahaman publik atas realitas politik Indonesia untuk kemudian mendukung kepemimpinannya, tapi sekaligus menunjukkan perilaku politiknya.

Analisis penelitian fokus pada berita, dan tidak secara langsung berhubungan dengan analisis penggunaan tokoh politik secara langsung. Namun, temuan penelitian kiranya sejalan dengan kajian dengan menggunakan analisis wacana kritis terhadap penggunaan bahasa dalam praktik wacana. Setidaknya, bahasa digunakan untuk meraih keuntungan politik melalui penempatan subjek tertentu atau dengan penggunaan bahasa tertentu yang membuat representasi aktor politik menjadi baik ataukah tidak. Apa yang dilakukan Vivanews.com tampaknya perluasan dari usaha para aktor politik untuk menampilkan dirinya sebagai "seseorang yang baik", dan dalam waktu bersamaan menonjolkan yang lain (pesaing politik) sebagai yang kurang baik (lihat Persada et al., 2018). Ini sekali lagi menegaskan bahwa media bukanlah entitas netral yang begitu saja menampilkan realitas. Sebaliknya, ia mempunyai agenda dan kepentingan politik. Oleh karena itu, kesadaran kritis adalah penting bagi pembaca. Dengan kesadaran kritis, pembaca dapat melihat kepentingan di balik konstruksi berita.

\section{KESIMPULAN}

Berdasarkan hasil pembahasan mengenai analisis bentuk ekspresi bahasa pilihan kata pada berita Pilpres 2019 di media Vivanews.com dapat disimpulkan adanya nilai eksperiensial, relasional, dan ekpresi. Nilai eksperiensial yang terdapat dalam berita Pilpres 2019 di media vivanews.com, yaitu menggunakan katakata dramatis, tegas, meyakinkan dan komunikatif. Kata-kata tersebut digunakan media untuk menciptakan efek ketertarikan, meyakinkan, dan menciptakan kesan tersendiri bagi pembaca berita. Nilai relasional, di sisi lain, menggunakan katakata berupa saran, kata formal berupa kosakata asing, dan kata informal berupa campuran bahasa daerah. Kata saran digunakan media untuk bersikap sopan dan tidak terlalu memojokan, sedangkan kosakata asing dan campuran bahasa daerah digunakan untuk menciptakan kesan komunikasi yang lebih akrab terhadap pembaca. Nilai ekspresif lebih mengekspresikan kata evaluasi yang bersifat negatif. Kata evaluasi digunakan media sebagai masukan yang merupakan bentuk kritik. 
Dari analisis ketiga nilai tersebut, dapat ditunjukkan bahwa penggunaan bahasa tidaklah netral. Penggunaan bahasa dalam berita politik selalu menyimpan keberpihakan, tergantung pada kelompok politik yang dibelanya. Ini berlangsung secara subtle sehingga suatu kesadaran kritis diperlukan bagi pembaca. dengan kesadaran kritis, pembaca dapat memilih kepentingan dan mungkin ideologi yang berada di balik berita.

\section{Daftar Pustaka}

Achsani, F. (2019). Tindak Tutur Direktif dan Implikatur Konvensional dalam Wacana Meme Dilan. Jurnal IMAJERI, 1(3), 1-10.

Adhiarso, D. ., Utari, P., \& Slamet, Y. (2017). Pemberitaan Hoax di Media Online Ditinjau dari Konstruksi Berita dan Respon Netizen. Jurnal Ilmu Komunikasi, 15(3), 215-225.

Ary Hunanda Kuswandari. (2017). Analisis Wacana: Representasi Pendidikan Indonesia pada Berita Online Detik.com. Metalingua, 15(2), 145152.

Fairclough, N. (1995). Critical Discours Analysis: The Critical Study of Language. In Addison Wesley Publishing Company. Addison Wesley Publishing Company.

Fairclough, N. (2003). Language and Power, Relasi Bahasa, Kekuasaan, dan Ideologi, terjemahan Indah Rohmani. Boyan Publishing.

Fazryansyah, M. I., Agustina, H., \& Nuruzzaman Nuruzzama. (2014). Manajemen Redaksional pada Surat Kabar Harian Utama Radar Cirebon. Jurnal ASPIKOM, 2(2), 85-102.

Fitriana Riri Amanda. (2019). Analisis Wacana Kritis Berita Online Kasus Penipuan Travel Umrah. Basindo:Jurnal Kajian Bahasa, Sastra Inndonesia, Dan Pembelajarannya, 3(1), 43-61.
Halliday, M. (1975). Learning how to mean - Explorations in the Development of Language. London: Arnold

Indah, R. N. (2009). Mengenal Lebih Dekat Analisis Wacana dan Kajian Bahasa Kritis. Universitas Islam Negeri Malang.

Kridalaksana. (2008). Kamus Linguistik. PT Gramedia Pustaka Utama.

Maiyulinda, C. (2018). Analisis Wacana Berita Liputan Khusus Kaltim Post tentang Pesta Pora di Tahura terhadap Kecenderungan Media dalam Menyadarkan Masyarakat Mengenai Penambangan Ilegal. Jurnal Ilmu Komunikasi, 6(1), 158172.

Mustafa, R. (2018). Ekspresi Bahasa dan Perspektif Rubrik Laporan Utama Majalah Hayamwuruk Jejak Kiri di Semarang. Jurnal Sastra Indonesia, Linguistik, 1-15.

Persada, Ikhwan, \& Syahrudin, J. (2018). A CRITICAL DISCOURSE ANALYSIS OF INDONESIA PRESIDENTIAL ELECTION IN 2014 GIVING SPEECHES IN CAMPAIGN DEBATE. JELL, 7(3), 1-10.

Prihantoro, E. (2013). Analisis Wacana Pemberitaan Selebriti pada Media Online. Proceeding PESAT (Psikologi, Ekonomi, Sastra, Arsitektur \& Teknik Sipil). 5, 51-57. 
Puji Rianto, R. I. (2014). Kepemilikan dan Intervensi Siaran, Perampasan Hak Publik, Dominasi, dan Bahaya Media di Tangan Segelintir Orang. Yogyakarta: PR2Media-Yayasan Tifa.

Rezaei, S., \& Nourali, N. (2016). Language and Power: The Use of Persuasive Techniques in Iran and U.S. President Speeches. Journal of Language Teaching and Research, 7(6), 12031209.

Sobur, A. (2009). Analisis Teks Media. Rosdakarya.
Sumarti, E. (2010). Analisis Wacana Kritis Strategi Politik Penggunaan Bahasa Dalam Pidato Presiden Susilo Bambang Yudhoyono. Litera, 9(1), 19-39.

tentang-kami. (n.d.). Www.Vivanews.Com. http://www.vivanews.com/tentangkami

Utami, C. J. (2019). Analisis Kosakata Bahasa Kekuasaan pada Harian Fajar. Universitas Negeri Makasar. 